\title{
How Does the Power of Crowdvoting Affect Purchase Decisions? Effects of Majority and Minority Influence in Online Rating Systems
}

\author{
Chi-Wen Chen \\ California State University Dominguez Hills \\ chchen@,csudh.edu
}

\begin{abstract}
Online rating systems gather review scores on products from different customers', creating collective opinions and accumulating the power formed by the crowdvoting. Such the power of the crowdvoting generates two influences: majority and minority influences. Both of which may form a signal that guides or misleads product/service evaluation and in turn purchase decision. This study draws from signaling theory to examine the effects of (1) majority, (2) minority influence and (3) number of reviewers on online shoppers' perceived product quality and perceived social risk and how they further influence purchase intention. We conducted a scenario-based experiment to test the research model and employed a $2 \times 2 \times 2$ full factorial design. A total of 371 undergraduates had participated. The results of this study suggest that majority influence increases perceived product quality and decreases perceived social risk, influencing shoppers' purchase decision. Implications for theory, practice, and future research directions are discussed.
\end{abstract}

\section{Introduction}

Online rating systems are one of online crowdbased systems that create online social networks in ecommerce websites and that have widely been used to implement crowdvoting practice and to leverage the power of the crowd [1]. Indeed, online shoppers today can take advantage of social shopping by checking review scores on products that other online shoppers have purchased. Specifically, the online rating systems generate an average review score that represents an aggregate evaluation of a group of reviewers' scores. This mass peer review process creates collective opinions, which forms a signal that may help or mislead online shoppers while evaluating a product, resulting in influencing their purchase decision-making process [2]. A variety of websites including shopping (e.g., Amazon.com), social networking (e.g., Facebook), and question-and-answer sites have taken advantage of such rating systems to improve their services, enhance social interaction among users, and provide a better social shopping experience for their websites [3-4]

Online rating systems consist of two major components: review scores and number of reviewers. These two components make other people become involved in the social shopping experience and accumulate power formed by the crowd. The first component comes from both an individual and a group of shoppers' review scores, where thereby generates two influences: majority and minority influences [5-6]. Majority influence reflects most of people's review scores whereas minority influence reflects an opposite and few or individual review score [6]. Applying this concept to online rating systems, this study proposes that these two influences may also take place in online rating systems as online rating systems allow online shoppers to receive average and individual review scores [7]. The average review score generates a majority influence in that the score represents a quick synopsis of the all reviewers' opinions. The individual review score, on the other hand, is the score that shows the personal opinion of an individual and thereby forms minority influence.

The second component of online rating systems, number of reviewers, can be viewed as the source of the power of crowd. Prior studies have found that the number of people in a group generates peer pressure and affects the likelihood that one will conform to the group's social norms. As the number increases, each individual has less of an impact [8]. Thus, the greater the number of reviewers in online rating systems, the greater the influences formed from the crowd may become.

To understand the impact of these two components (i.e., majority and minority influences, and number of reviewers) on online shoppers is important for three 
reasons. First, people are increasingly buying noncommodity, physical, and in many events higher priced products such as clothing that requires trying on, fresh produce which are touch-n-feel products, and electronics in an online environment [9]. Therefore, risk caused by the uncertainty of the online environment is very likely to happen [9-10]. Majority and minority influences, and number of reviewers may form an essential signal to help online shoppers mitigate risks in online environments. Therefore, online shoppers may rely on the results of the review score to reduce product performance risk [7]. Also, online shoppers can and get social support by other shoppers' review scores because review scores show most people's opinions, resulting in lower social risk (i.e., people' perception of other individuals regarding their online purchasing decisions) [11].

Second, some online shoppers tend to use heuristic decision-making strategies by speeding up the process of finding a satisfactory solution to ease the cognitive load of decision making [12]. As a result, they may follow peer opinions by relying on average review score and/or number of reviewers. Such the shortcut information, while quick and reducing workload, may cause a problem of misleading information, resulting in cognitive bias and making a wrong purchase decision [12].

Additionally, although the usage of online rating systems is growing rapidly, there is a lack of understanding of how such type of online social networks in e-commerce websites can provide support and influence purchase decisions. Specifically, several papers have found that review scores increase the probability of purchase [13-15]. However, prior literature in this line of research focus on either the average review score $[13,15]$ or individual review score [7] but not both simultaneously. This study summarizes the previous literature in Table 1.

Table 1. Previous Literature

\begin{tabular}{|c|l|c|}
\hline $\begin{array}{c}\text { Authors } \\
\text { (Year) }\end{array}$ & \multicolumn{1}{|c|}{ Research Findings } & Research Gap \\
\hline $\begin{array}{c}\text { Gu, Park } \\
\text { and Konana } \\
\text { Year } \\
(2011)[13]\end{array}$ & $\begin{array}{c}\text { Product reviews have } \\
\text { a significant impact on } \\
\text { the retailer's sales. }\end{array}$ & $\begin{array}{c}\text { Only consider } \\
\text { product reviews } \\
\text { in general. }\end{array}$ \\
\hline $\begin{array}{c}\text { Zhu and } \\
\text { Zhang } \\
(2010)[15]\end{array}$ & $\begin{array}{l}\text { Online reviews are } \\
\text { more influential for } \\
\text { less popular games } \\
\text { and games whose } \\
\text { players have greater } \\
\text { Internet experience. }\end{array}$ & $\begin{array}{c}\text { Only consider } \\
\text { product reviews } \\
\text { in general. Do not } \\
\text { consider majority } \\
\text { or minority. }\end{array}$ \\
\hline $\begin{array}{c}\text { Chen, } \\
\text { Dhanasobh } \\
\text { on, and }\end{array}$ & $\begin{array}{l}\text { The impact of reviews } \\
\text { at a disaggregate level } \\
\text { has a stronger impact }\end{array}$ & $\begin{array}{c}\text { Consider minority } \\
\text { influence but not } \\
\text { majority }\end{array}$ \\
\hline
\end{tabular}

\begin{tabular}{|c|l|c|}
\hline $\begin{array}{c}\text { Smith } \\
\text { (2008) [7] }\end{array}$ & $\begin{array}{l}\text { on less popular books } \\
\text { than on more popular } \\
\text { books. }\end{array}$ & influence. \\
\hline & $\begin{array}{l}\text { Review depth has a } \\
\text { positive effect on the } \\
\text { helpfulness of the } \\
\text { review, but the product } \\
\text { type moderates the } \\
\text { effect of review depth } \\
\text { Mudambi, } \\
\text { and Schuff helpfulness of } \\
\text { (2010) [2] }\end{array}$ & $\begin{array}{c}\text { Focus on } \\
\text { helpfulness of the } \\
\text { review but do not } \\
\text { consider majority } \\
\text { or minority. }\end{array}$ \\
& \\
\hline
\end{tabular}

To the authors' knowledge, no study combines average and individual review scores and number of reviewers. This raises the question of how average review scores interact with individual review scores (i.e., how majority influence interacts with minority influence) or number of reviewers, and how the interactions of these factors create a signal, showing product quality, reducing social risks and in turn affecting the sequent behavior (i.e., intention to purchase). To fill this gap, this study draws from signaling theory to examine the effects of (1) majority, (2) minority influence and (3) number of reviewers on online shoppers' perceived product quality and perceived social risk and how they further influence purchase intention. The results of this study can contribute and extend the existing knowledge on how the power of crowdvoting including minority and majority influence is formed in online rating systems and how it influences or misleads desired behavior.

The remainder of the article is organized as follows. The next section reviews the literature and presents the theoretical foundation for this study. The following section develops hypotheses and research framework. The subsequent section describes the research methodology and procedures for the collection of data. Finally, potential contributions and directions for further research are presented.

\section{Theoretical Foundation}

\subsection{Signaling theory}

The signaling theory provides a basis for understanding how two parties (e.g., buyer and seller) address unobservable or unclear information in prepurchase contexts [16]. It basically argues that prior to the purchase, buyers and sellers possess asymmetric information toward a product because while the product quality is clear to the seller, it is opaque to buyers [16], particularly for those products that contain experience properties such as the reliability of a personal computer since it is unobservable [17]. This differential level of information from two sides can be 
shortened after buyers purchase the product as they can experience the product by using it. Signaling theory suggests that, to deal with the issue of information asymmetry, sellers have to send a pre-purchase signal to let buyers assess the product quality and to make a distinction from other low-quality sellers [18].

To know how to provide an effective and efficient signal, several studies have investigated different signals that may facilitate buyers to evaluate the product quality including price [19], brand [20] and warrants [18]. Recently, the signaling theory has been applied in the context of e-commerce and intent to understand how websites' attributes such as layout or design may form a signal for mitigating uncertainty [10] and helping assess the product quality [21].

An average review score in an online shopping website can be viewed as a cue [22], signaling the information to help those buyers who have to compare different cases but do not have sufficient knowledge for the product. This study is based on this theory to develop the hypotheses and proposes that the average review score forms the power of the crowdvoting, creating a product quality and social signal that influences purchase decisions.

\subsection{Majority versus minority influence}

A signal formed by majority and minority sources creates different influences. A signal formed by majority sources typically generate the normative position (i.e., opinions that reflect most of people's beliefs), whereas a signal formed by minority sources generate an anti-normative position [23]. Most of the contemporary research that focuses on majority and minority influence attempt to examine how a persuasive cue from majority and minority influences attitude and intention change, and whether majority influence is more powerful than minority influence [24]. People who comply with the majority position tend not to consider it in detail because they believe that most people's opinions are likely to be correct [25]. For this reason, it is easier to go along with the majority, and so people do so, even if they privately disagree [24]. In this case, attitude shift occurs at the public, overt level to be part of the majority group, which is called compliance [24]. In contrast, people tend to consider the minority's arguments in detail by examining its content [25]. As people do not wish to be seen to agree with the minority in public, attitude shift tends to be more evident in private, subconscious-level opinion, which is called conversion [26].

This study is based on the effect of majority and minority influences and proposes that both majority and minority influences may coexist when online shoppers use online rating systems. Specifically, an online purchasing process generally involves two steps when online shoppers use rating systems: first, they tend to scan the average review score to select a small number of candidate products. Second, then they look more deeply into individual rating scores for the smaller set of products, which often include some written comments [7]. This study proposes that the first step induces majority influence. In this step, online shoppers make selection based on the average review scores and comply with the majority position by focusing on the high average review scores. The second step introduces minority influence. Online shoppers tend to check the average review score in detail by understanding the minority's arguments. Therefore, both majority and minority influence will be considered in this study.

\section{Research framework and hypotheses}

\subsection{Effects of average review score on perceived product quality and social risk}

Previous studies have found that signals formed in online shopping websites influence users in two different ways: by increasing perceived product quality $[21,27]$ and by reducing perceived risk [28]. When online shoppers, for example, can receive a more complete signal from a website, this signal helps them evaluate an item and acquire better understanding of the item, which in turn enhances perceived product quality [21]. On the other hands, during online shopping, online shoppers may face several different risks when making a purchasing decision (see [11], p. 263). Among them, social risk is the risk that is highly relevant with the crowd. It can be defined as "the potential loss of status in one's social group as a result of adopting a product or service, looking foolish or untrendy" [11]. In other words, perceived social risk is concerned with people' perception of other individuals regarding their online purchasing decisions [29]. In shopping websites, this risk can be mitigated as online shoppers can receive the information regarding most of the reviewers' opinions based on the results of review scores. This study proposes that if they purchase an item with a high average review score, it is very likely that the perceived social risk will be lower because they comply with most reviewers' opinions. In contrast, online shoppers may perceive a higher social risk when they purchase a product that most reviewers do not like (i.e., low review scores).

Therefore, this study proposes that average review scores can be treated as a signal, messaging potential product quality $[7,15]$ and mitigating social risk in the 
purchase decision. Thus, the following hypotheses are proposed:

Hypothesis 1: Average review score is positively related to perceived product quality

Hypothesis 2: Average review score is negatively related to perceived social risk

\subsection{Individual review score}

An individual review score will be processed when shoppers are interested in an item and want to look more deeply into individual ratings to check the item's pros and cons [7]. The individual review score is formed by personal opinion, which generates minority influence. Because users are able to see both average and individual review scores during online shopping, majority versus minority influence may occur in the online purchase decision.

With the absence of minority influence, the influence is dominated by the majority, and online shoppers are more likely to comply with majority opinions [30]; however, when minority influence also exists (i.e., individual ratings are available), the interaction, conflict, and imbalance of majority versus minority influences become stronger, particularly in a situation in which majority and minority opinions take different positions [5,30]. The signal formed by both majority and minority influence may thereby become more diverse (i.e., including opposite positions) and uncertain, resulting in more complex information processing.

In the context of online shopping websites (e.g., Amazon.com), individual review scores are displayed in a way such that both favorable (i.e., higher ratings) and critical (i.e., lower ratings) review scores are compared and presented side by side. This way, according to majority versus minority influence, the conflict and imbalance of information processing will be more salient $[5,6]$, and the signal received by online shoppers will contain more noise (i.e., more varying opinions are presented to shoppers). Therefore, this study proposes the following hypotheses:

Hypothesis 3: Average review score will more positively influence perceived product quality when there is no individual review score than when there is an individual review score.

Hypothesis 4: Average review score will negatively influence perceived social risk less when there is no individual review score than when there is an individual review score.

\subsection{Number of reviewers}

Online rating systems provide information regarding how many reviewers have rated a product. This information strengthens the power of the crowd. Prior studies on the effect of the number of people in the group have suggested that the number of people creates two types of influence: information influence and normative influence [31]. Informational influence occurs in ambiguous situations where users have to make a decision. Because they do not know the appropriate course of action, they tend to rely on the "strength in numbers" of the majority's position because they believe that majority judgments are likely to be correct [31]. Normative influence occurs in situations where users are concerned not so much about truth as about being socially accepted. In other words, individuals want to be accepted and therefore wish to avoid disapproval [8]. These two influences suggest that the number of people in the group affects the likelihood that one will conform to the group's social norms. As the number increases, each individual has less of an impact [8].

In the context of shopping websites, the number of reviewers shown in online rating systems is the aggregated information that can form a power. According to informational and normative social influences, this power strengthens a signal formed by average ratings in the way that as the number of reviewers increases, the influence of the group ratings increases, and vice versa. Thus, this study proposes the following hypotheses:

Hypothesis 5: Average review score will more positively influence perceived product quality when there is a high number of reviewers than when there is a low number.

Hypothesis 6: Average review score will negatively influence perceived social risk less when there is a high number of reviewers than when there is a low number.

\subsection{Perceived product quality, perceived social risk and purchase intention}

There is both theoretical and empirical support in information systems and marketing literature that perceived product quality and perceived social risk are determinants of purchase intentions [21, 32-33]. These two factors play an even more important role in the online environment as online shoppers cannot touch and inspect a product immediately, resulting in the lack of product quality signals [21] and full uncertainty in online shopping [33]. Therefore, when online shoppers can perceive a high level of product quality, this perception will increase the belief that the product is 
worth purchasing [32]. Also, according to normative influence, when online shoppers want to be accepted and to avoid disapproval, they may make a decision that complies with majority opinions [8]. A large body of research has found that perceived product quality is positively, but perceived social risk is negatively, associated with online purchase intention [11, 21]. Collectively, we propose the following hypotheses:

Hypothesis 7: Perceived product quality will positively influence intention to purchase.

Hypothesis 8: Perceived social risk will negatively influence intention to purchase.

The research model is shown below.

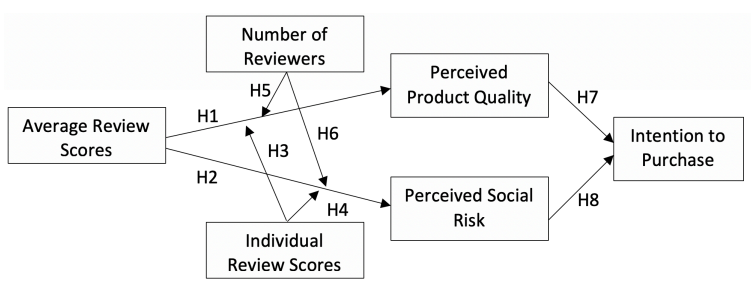

Figure 1. Research Model

\section{Methodology}

For the experiment, this study employed a $2 \times 2 \times 2$ full factorial design where this study manipulated average review score (low versus high), number of reviewer (low versus high) and individual review score (no versus with) to test all hypotheses.

The subjects were undergraduate students at a major Northeastern US University and they participated in the experiment for class credit. They were presented with a scenario that asked them to take part in an online purchasing task. They were then randomly assigned to one of the conditions by an online survey system.

For the purpose of the experiment, this study designed a simple website of a hypothetical shopping store. In the no individual review score condition, the first screen of the experimental interface shows the digital camera with product descriptions, prices, rating results, and the number of reviewers. In the individual review score condition, individual review scores including positive review score and negative review score are added in the experiment. After reading all information, they have to click the "next" button and start filling out the questionnaire. To control for possible confounding effects, this study takes the digital camera's brand out.
This study uses digital cameras as the product for three reasons: (1) the subjects are students who are relatively familiar with digital cameras [34]; (2) digital cameras are goods that involve greater depth of decision processes [2]; and (3) digital cameras have been used widely in e-commerce studies [8] and rating system studies [2].

\subsection{Manipulation}

The experimental factors were designed as follows: (1) Review score: we manipulated the high average review score as 4.5 stars and the low average review score as 1.5 stars. The reason that this study uses these two scores to represent high and low review score is because prior studies have indicated that J-shape distribution of review score is the most common score distribution [14]. To reflect the real situation, this study thereby manipulated 4.5 and 1.5 stars respectively. (2) Number of reviewers: this study manipulated number of reviewers by varying the number as 10 (low) and 621 (high). This classification was evaluated in a pretest $(\mathrm{N}=50)$ that confirmed that the high number of reviewer $($ Mhigh $=5.30)$ was perceived as significantly higher than the low number of reviewer $(\mathrm{Mlow}=2.47 ; \mathrm{F}$ $=151.133 ; \mathrm{p}<.001)$. The scale was an agree-disagree scale where 7 suggested "high number of reviewers" and 1 suggested "low number of reviewers". (3) Individual review score: several websites such as Amazon.com or drugstore.com use individual scores in the way that shows both negative and positive score in order to help users understand pros and corns of an item. To reflect this fact, this study manipulated individual review scores by showing both positive and negative individual review scores.

The screenshot for one of experimental conditions is shown in Figure2.

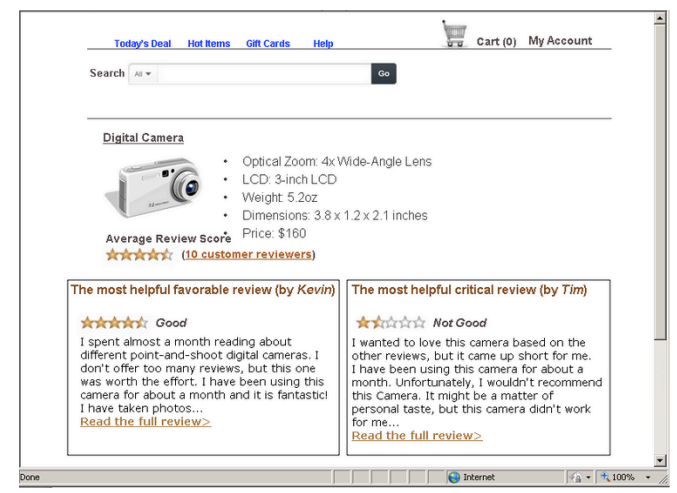

Figure 2: Screenshot of one of experimental condition website 


\subsection{Measures}

Measurement items were all adapted from prior literature. Perceived product quality was measured using Dodds et al., (1991) [32]'s 5-item scales. Perceived social risk was assessed with items adapted from Crespo et al., (2009) [11]. Purchase intention was adapted from Chen (2017) [35]. Additionally, product knowledge and product involvement are important variables that can influence the results. To minimize the influence of these variables on dependent variables, product knowledge and product involvement were measured and used as the control variables in the analysis. Product knowledge and product involvement were measured using Park and Moon's (2003) 3-itmes scale [36].

\subsection{Participants}

A total of 371 undergraduates have participated in the study. Demographic variables, including gender and age are presented in Table 2.

Table 2. Subject Demographics

\begin{tabular}{|c|c|c|c|}
\hline Variables & $\begin{array}{c}\text { Frequency } \\
(\%)\end{array}$ & Variables & $\begin{array}{c}\text { Frequency } \\
(\%)\end{array}$ \\
\hline Gender & & $\begin{array}{c}\text { Internet } \\
\text { Experience }\end{array}$ & \\
\hline Male & $190(51.2 \%)$ & $\begin{array}{c}\text { Less than } 1 \\
\text { year }\end{array}$ & 0 \\
\hline Female & $181(48.8 \%)$ & $1-2$ year & $1(2 \%)$ \\
\hline Age & & $3-5$ years & $22(5 \%)$ \\
\hline $18-20$ & $152(41.0 \%)$ & $6-8$ years & $87(23 \%)$ \\
\hline $21-23$ & $152(41.0 \%)$ & $9-10$ years & $101(27 \%)$ \\
\hline $24-26$ & $42(11.3 \%)$ & $11-13$ years & $107(28 \%)$ \\
\hline $27-29$ & $18(4.9 \%)$ & $14-15$ years & $28(8 \%)$ \\
\hline Over 30 & $7(1.8 \%)$ & Over 16 years & $25(7 \%)$ \\
\hline
\end{tabular}

\section{Results}

\subsection{Factor analysis}

Factor analysis was conducted to examine whether each item loads correctly to each factor. The result is summarized in Table 3. Please note that control variables were in factor analysis because this study needs to make sure these all items were loaded to each factor including control variables correctly. The result shows that all items were loaded to each factor. The reliability for each factor was conducted. All factors are over 0.7, showing the factors are reliable.

Table 3. Result of Factor Analysis with a Promax Rotation

\begin{tabular}{|c|c|c|c|c|c|c|}
\hline Items & \multicolumn{4}{|c|}{ Component } & Cronbach's & $\begin{array}{l}\text { Mean (SD) } \\
\mathrm{N}=371\end{array}$ \\
\hline INV1 & 0.911 & -0.001 & 0.032 & 0.057 & \multirow{10}{*}{0.973} & \multirow{10}{*}{$4.77(1.39)$} \\
\hline INV2 & 0.881 & 0.031 & 0.004 & 0.096 & & \\
\hline INV3 & 0.924 & -0.021 & 0.05 & 0.092 & & \\
\hline INV4 & 0.89 & -0.011 & -0.022 & 0.066 & & \\
\hline INV5 & 0.914 & 0.04 & -0.1 & 0.103 & & \\
\hline INV6 & 0.897 & -0.028 & 0.014 & 0.066 & & \\
\hline INV7 & 0.84 & 0.031 & -0.072 & 0.047 & & \\
\hline INV8 & 0.891 & 0.01 & -0.07 & 0.089 & & \\
\hline INV9 & 0.884 & 0.011 & -0.098 & 0.107 & & \\
\hline $\begin{array}{c}\text { INV } \\
10\end{array}$ & 0.911 & 0.008 & 0.054 & 0.107 & & \\
\hline PQ1 & 0.007 & 0.934 & -0.152 & 0.011 & & \\
\hline PQ2 & 0.02 & 0.897 & -0.101 & 0.019 & & \\
\hline PQ3 & 0.06 & 0.903 & -0.102 & -0.065 & 0.958 & $3.59(1.38)$ \\
\hline PQ4 & 0.005 & 0.932 & -0.1 & 0.034 & & \\
\hline PQ5 & 0.006 & 0.926 & -0.128 & 0.013 & & \\
\hline PSR1 & -0.037 & -0.135 & 0.859 & -0.021 & & \\
\hline PSR2 & -0.035 & -0.103 & 0.866 & 0.003 & 0.836 & $3.24(1.37)$ \\
\hline PSR3 & -0.017 & -0.238 & 0.829 & -0.017 & & \\
\hline PK1 & 0.402 & -0.007 & -0.091 & 0.74 & $08-8$ & $14(146$ \\
\hline PK2 & 0.079 & 0.011 & 0.037 & 0.903 & 0.82 & $4.14(1.46)$ \\
\hline
\end{tabular}

Note. INV: involvement; PQ: perceived product quality; PSR: perceived social risk; PK: product knowledge.

\subsection{Perceived product quality}

To test hypothesis 1 , hypothesis 3 and hypothesis 5 , this study conducted ANCOVAs for perceived product quality and perceived social risk with the eight experimental conditions as the independent variables and product knowledge and product involvement as the covariate. Table 4 shows the result of ANCOVA. The average review score had a significantly positive impact on perceived product quality. When the average review score is high, online shoppers will perceive a high product quality, indicating support for Hypothesis 1.

Table 4. Results of ANCOVA (Dependent Variable: Perceived Product Quality)

\begin{tabular}{|c|c|c|c|c|}
\hline Source & d.f. & $\begin{array}{c}\text { Mean } \\
\text { Square }\end{array}$ & $\mathrm{F}$ & $\mathrm{p}$-value \\
\hline Corrected Model & 7 & 40.180 & 34.337 & $.000^{* * *}$ \\
\hline Intercept & 1 & 306.691 & 262.090 & $.000^{* * *}$ \\
\hline Average Review Score & 1 & 234.353 & 200.271 & $.000^{* * *}$ \\
\hline Product Knowledge & 1 & 1.122 & .959 & .328 \\
\hline Product Involvement & 1 & 1.010 & .863 & .354 \\
\hline $\begin{array}{c}\text { Average Review Score } * \\
\text { Individual Review Score }\end{array}$ & 2 & 9.702 & 8.291 & $.000^{* * *}$ \\
\hline $\begin{array}{c}\text { Average Review Score } * \\
\text { Number of Reviewers }\end{array}$ & 2 & 15.549 & 13.288 & $.000^{* * *}$ \\
\hline $\begin{array}{c}\text { Error } \\
* * * \mathrm{p}<0.001 * * \mathrm{p}<0.01 * \mathrm{p}<0.05\end{array}$ & 363 & 1.170 & & \\
\hline
\end{tabular}

Furthermore, the effect of average review score combined with individual review score or with number of reviewers significantly influenced perceived product quality. Estimated marginal means (see Table 5) suggest that the interaction between average review score and individual review score increased perceived product quality, which does not support for Hypothesis 3 , suggesting that perceived product quality still increases when there is an individual review score. 
As shown in Table 4, the interaction between average review score and number of reviewers significantly influence perceived product quality (see Table 4). When there are high average review score and high number of reviewers, perceived product quality would be high, indicating support for Hypothesis 5.

Table 5. Estimated Marginal Means for Perceived Product Quality

\begin{tabular}{|c|c|c|c|c|c|}
\hline \multicolumn{2}{|c|}{ Conditions } & Mean & $\begin{array}{c}\text { St. } \\
\text { Error }\end{array}$ & $\begin{array}{l}\text { Lower } \\
\text { Bound }\end{array}$ & $\begin{array}{l}\text { Upper } \\
\text { Bound }\end{array}$ \\
\hline \multicolumn{2}{|c|}{ Low Average Review Score } & 2.809 & .079 & 2.653 & 2.965 \\
\hline \multicolumn{2}{|c|}{$\begin{array}{l}\text { High Average Review } \\
\text { Score }\end{array}$} & 4.409 & .080 & 4.252 & 4.566 \\
\hline \multirow{2}{*}{$\begin{array}{c}\text { Low } \\
\text { Average } \\
\text { Review } \\
\text { Score }\end{array}$} & Review Score & 2.490 & .113 & 2.268 & 2.712 \\
\hline & $\begin{array}{l}\text { High Individual } \\
\text { Review Score }\end{array}$ & 3.129 & .112 & 2.909 & 3.349 \\
\hline \multirow{2}{*}{$\begin{array}{c}\text { High } \\
\text { Average } \\
\text { Review } \\
\text { Score }\end{array}$} & $\begin{array}{l}\text { Low Individual } \\
\text { Review Score }\end{array}$ & 4.359 & .112 & 4.139 & 4.579 \\
\hline & $\begin{array}{c}\text { High Individual } \\
\text { Review Score }\end{array}$ & 4.459 & .115 & 4.234 & 4.684 \\
\hline \multirow{2}{*}{$\begin{array}{c}\text { Low } \\
\text { Average } \\
\text { Review } \\
\text { Score }\end{array}$} & $\begin{array}{c}\text { Low Number of } \\
\text { Reviewers }\end{array}$ & 2.896 & .113 & 2.675 & 3.118 \\
\hline & $\begin{array}{c}\text { High Number of } \\
\text { Reviewers }\end{array}$ & 2.722 & .112 & 2.502 & 2.943 \\
\hline \multirow{2}{*}{$\begin{array}{c}\text { High } \\
\text { Average } \\
\text { Review } \\
\text { Score }\end{array}$} & $\begin{array}{c}\text { Low Number of } \\
\text { Reviewers }\end{array}$ & 4.005 & .112 & 3.786 & 4.225 \\
\hline & $\begin{array}{c}\text { High Number of } \\
\text { Reviewers }\end{array}$ & 4.812 & .115 & 4.587 & 5.038 \\
\hline
\end{tabular}

Table 6 shows the result of ANCOVA. The average review score had a significant impact on perceived social risk, indicating support for Hypothesis 2.

Table 6. Results of ANCOVA (Dependent Variable: Perceived Social Risk)

\begin{tabular}{|c|c|c|c|c|}
\hline Source & d.f. & Mean Square & $\mathrm{F}$ & $\mathrm{p}$-value \\
\hline Corrected Model & 7 & 9.726 & 5.556 & $.000^{* * *}$ \\
\hline Intercept & 1 & 283.456 & 161.932 & $.000^{* * *}$ \\
\hline Average Review Score & 1 & 62.773 & 35.861 & $.000^{* * *}$ \\
\hline Product Knowledge & 1 & 1.329 & .759 & .384 \\
\hline Product Involvement & 1 & .133 & .076 & .783 \\
\hline $\begin{array}{c}\text { Average Review Score } \\
\text { Individual Review Score }\end{array}$ & 2 & .172 & .098 & .906 \\
\hline $\begin{array}{c}\text { Average Review Score } \\
\text { Number of Reviewer }\end{array}$ & 2 & .735 & .420 & .657 \\
\hline \multicolumn{6}{|l|}{ Error } & 363 & 1.750 & & \\
\hline$* * * \mathrm{p}<0.001^{* *} \mathrm{p}<0.01^{*} \mathrm{p}<0.05$ & & & \\
\hline
\end{tabular}

Estimated marginal means (see Table 7) suggest that the high average review score leads to low perceived social risk $($ mean $=2.827)$ while low average review score lead to high perceive social risk $($ mean $=$ 3.654).

However, no interaction effects were significant, suggesting that perceived social risk was not influenced by the interactions between average review score and individual review score or average review score and number of reviewers. Thus, Hypothesis 4 and 6 were not supported.
Table 7. Estimated Marginal Means for Perceived Social Risk

\begin{tabular}{|l|c|c|c|c|}
\hline & Mean & $\begin{array}{c}\text { St. } \\
\text { Error }\end{array}$ & $\begin{array}{c}\text { Lower } \\
\text { Bound }\end{array}$ & $\begin{array}{c}\text { Upper } \\
\text { Bound }\end{array}$ \\
\hline $\begin{array}{l}\text { Low Average } \\
\text { Review Score }\end{array}$ & 3.654 & .097 & 3.464 & 3.845 \\
\hline $\begin{array}{l}\text { High Average } \\
\text { Review Score }\end{array}$ & 2.827 & .098 & 2.634 & 3.019 \\
\hline
\end{tabular}

5.3 The Relationship between perceived product quality, perceived social risk and intention to purchase

The relationships between perceived product quality, perceived social risk and intention to purchase were examined using multiple-regression. The result is shown in Table 8.

The regression was significant with an $\mathrm{R}$ square of 0.031 . There was no collinearity detected (VIF values were 1.103) and the standardized residuals were normally distributed. The results suggest that the perceived product quality is positively associated with intention to purchase with a standardized $\beta=0.546$ $(\mathrm{p}<0.001)$, providing support for Hypothesis 7 . Perceived social risk is negatively associated with intention to purchase with a standardized $\beta=-0.094$ $(\mathrm{p}<0.05)$, providing support for Hypothesis 8 .

Table 8. Linear Regression for Intention to Purchase

\begin{tabular}{|c|c|c|c|c|c|}
\hline Variable & $\mathrm{B}$ & $\mathrm{t}$ & $\mathrm{p}$-value & Tolerance & VIF \\
\hline (Constant) & & 1.919 & 0.056 & & \\
\hline $\begin{array}{c}\text { Perceived } \\
\text { Quality }\end{array}$ & 0.546 & 12.262 & $0.000^{* * *}$ & 0.906 & 1.103 \\
\hline $\begin{array}{c}\text { Perceived } \\
\text { Social Risk }\end{array}$ & -0.094 & -2.101 & $0.036^{* *}$ & 0.906 & 1.103 \\
\hline $\begin{array}{l}\mathrm{F}=7.004(\mathrm{p}<0.01), \text { Adjusted } \mathrm{R}^{2}=0.031 \\
* * * \mathrm{p}<0.001 * * \mathrm{p}<0.01 * \mathrm{p}<0.05\end{array}$
\end{tabular}

\section{Discussion and conclusion}

Online rating systems are one of online crowdbased systems that create online social networks in ecommerce and form the power of crowdvoting. The goal of this study is to understand how does the power of crowdvoting in online rating systems affect online shoppers' purchase decisions. The results suggest that the signal formed by the average review score positively influences perceived product quality and reduces perceived social risk, which in turn increases online shoppers' intention to purchase. The primary findings of this study are summarized as follows.

First, drawing on signaling theory, this study has found that average review scores form a signal that generates a positive relationship with perceived product quality (Hypothesis 1), but that causes a negative relationship with perceived social risk 
(Hypothesis 2). These results are consistent with the findings of the previous studies regarding the effect of the signal generated by extrinsic cues such as ratings on shoppers' perceptions. Additionally, the results for hypothesis 3 indicate that average review scores combined with individual review scores, which include both positive and negative reviews, would result in higher perceived product quality than when there is no individual rating. This finding is not in line with prior studies examining the effect of product reviews on shoppers' judgment [7, 13]. The result is surprising. The possible explanation for this discrepancy is that when minority influence violates the expectations of majority influence, the conflict and imbalance may occur, leading to a systematic information processing $[5,30]$. This systematic information processing could enhance rather than inhibit the perception of product quality. In other words, although the violation occurs, it can be viewed as a complement signal, giving users more information and helping them make decisions. Thus, the combination of both average review scores and individual review scores will increase rather than decrease perceived product quality. Additionally, hypothesis 4 was not supported, suggesting that average review scores combined with the individual review score may not decrease perceived social risk. The possible reason is that an average review score is calculated based on a group review scores from multiple reviewers. In other words, the average review score represents most of the reviewers' opinions, which reduces perceived social risk. As a result, while individual review scores have different opinions, those minor opinions are not strong enough to significantly increase perceived social risk.

As to number of reviewers, the results show that average review scores aggregated by a high number of reviewers had a stronger impact on perceived product quality than by a low number of reviewers (hypothesis 5). This result supports that the power of the crowdvoting can be generated in online rating systems, strengthening the signal of the product quality, which is consistent with prior studies that focus on the signaling theory $[21,22]$. However, hypothesis 6 was not supported, indicating that average review scores generated by different numbers of reviewers (i.e., low vs. high) may not result in mitigating perceived social risk. This result is surprising. The possible explanation is that while average review scores may come from only few reviewers (e.g., two reviewers), it still represents majority opinions. Therefore, regardless of how many reviewers are counted in average, it still creates a crowd signal that reduces perceived social risk.

Finally, consistent with the findings of the prior studies $[11,21]$, the results reveal that perceived product quality is positively while perceived social risk is negatively associated with intention to purchase (hypothesis 7 and 8).

\subsection{Theoretical implications}

The major theoretical contribution of this study is the development of a research model that extends the signaling theory by combining it with majority versus minority influences. The results show that both majority and minority opinions generated in rating systems can form the signal, increasing online shoppers' perception of product quality and in turn intention to purchase. Furthermore, prior studies utilizing signaling theory primarily focus on website characteristics [21] or product characteristics such as price [19], brand [20], warrants [18]. To authors' knowledge, this study is the first one that validates the signaling theory by introducing it into the context of online rating systems, which have widely been used to create online social networks in online shopping websites.

Additionally, while there is considerable literature that focuses on the impact of majority and minority influences on shoppers' attitude, little academic research has been devoted to examine how the number of people influences the power of the majority influence. This study contributes the effect of majority versus minority influence by showing that different numbers of reviewers may create different degrees of majority influence. Specifically, this study found that the signal formed by rating systems would be strengthened and becomes much stronger when majority influence is created by higher number of reviewers than by lower number of reviewers. When the power of the majority influence becomes very strong (i.e., generated by a lot of users), it would dominate the influence and minority influence would not be influential to perceived product quality. However, perceived social risk would not be affected significantly.

\subsection{Practical implications}

The findings of this research will be of interest to managers and web designers. This research provides essential implications for web design and helps managers to understand how to leverage the online rating systems to create a signal that affects online shoppers' subsequent behavior (e.g., intention to purchase). One of managerial implications is that overemphasizing on getting high review scores without considering the effect of the number of reviewers may 
not have a significant impact on perceived product quality. Therefore, product managers who attempt to take an advantage of the online rating system in creating a positive signal to online shoppers need to know that the signal formed by online rating systems is composed of two components - reviewer scores and number of reviewers. Both elements need to be considered together so that the signal can positively influence perceived product quality. Furthermore, product mangers also need to leverage individual review scores because it may provide the complement information for users in evaluating product quality. Accordingly, users may perceive product quality easily as it will strengthen the signal, leading to intention to purchase. Additionally, the more users contributing their review score, the stronger the signal will be generated. Thus, as to web designers, they have to create a user-friendly online rating system in order to motivate and encourage users to contribute review scores.

\subsection{Limitations and further research}

Despite the empirical support for the proposed model and the contributions of this study, we acknowledge some theoretical and empirical limitations, which call for additional research. First, due to the cross-sectional design of this study, as opposed to a longitudinal study, the direction of causality cannot be determined based on our statistical analyses. Causality can only be inferred through the theory. Furthermore, this study cannot analyze longitudinal processes, such as how average review scores, individual review scores and number of reviewers influence perceived product quality and perceived social risk over time. Thus, further research can improve this study by conducting the longitudinal study in order to capture the dynamic changes of all variables proposed in the model. Second, the results are somewhat affected by the inherent limitations of a scenario-based experiment. This study designed a simple website of a hypothetical shopping store in the experiment rather than used a real website in the field. It is possible that subjects could potentially respond differently to a hypothetical scenario than they would in a real scenario. This study thereby calls for further studies to validate the findings of this study by conducting a field study. Third, as to the issue of external validity, this study acknowledges the variations and different types of shopping websites and products. This study only focuses on the digital camera in a business-to-consumer shopping website. Caution must be exercised when attempting to generalize the results to different products in varied contexts such as online auctions or group buying websites. Therefore, future studies can take product types and different contexts into consideration in the research model.

\subsection{Conclusion}

An online rating system is a social networking system in an online shopping website. An increasing number of e-commerce websites use it to leverage collective opinions, to implement crowdvoting practice and to influence purchase decisions. This study is an encouraging first step toward understanding the impacts of the average review score, individual review score, and number of reviewers on users' perceptions of product quality and social risk, and how they further influence purchase decisions. The results of this study provide a fundamental framework and open an avenue for future research to explore more comprehensive studies and to better understand this increasingly important topic.s

\section{References}

[1] J. Howe, "The rise of crowdsourcing," Wired, 2006. 14(6), pp. 1-4

[2] S. M. Mudambi, and D. Schuff, "What makes a helpful online review? A study of customer reviews on Amazon. com," MIS Quarterly, 2010. 34(1), pp. 185-200.

[3] A. Ansari, S. Essegaier, and R. Kohli, "Internet Recommendation Systems," Journal of Marketing research, 2000, 37(3), pp. 363-375.

[4] N. Kumar, and I. Benbasat, "Research note: the influence of recommendations and consumer reviews on evaluations of websites," Information Systems Research, 2006, 17(4), pp. 425-439.

[5] S. M. Baker, and R. E. Petty, "Majority and minority influence: Source-position imbalance as a determinant of message scrutiny," Journal of Personality and Social Psychology, 1994, 67(1), pp. 5-19.

[6] R. Martin, and M. Hewstone, "Majority versus minority influence: When, not whether, source status instigates heuristic or systematic processing," European Journal of Social Psychology, 2002, 33(3), pp. 313-330.

[7] P-Y. Chen, S. Dhanasobhon, and M.D. Smith, “All reviews are not created equal: The disaggregate impact of reviews and reviewers at Amazon.com," 2008, Available at SSRN: https://ssrn.com/abstract=918083 or http://dx.doi.org/ $10.2139 /$ ssrn. 918083

[8] R. B. Cialdini, and N. J. Goldstein, "Social influence: compliance and conformity," Annual Review Psychology, 2004, (55), pp. 591-621.

[9] A. Kirmani, and A. R. Rao, "No pain, no gain: A critical review of the literature on signaling unobservable product quality," The Journal of Marketing, 2000, 64(2), pp. 66-79.

[10] P. A. Pavlou, H. Liang, and Y. Xue, "Understanding and mitigating uncertainty in online exchange relationships: A principal-agent perspective," MIS Quarterly, 2007, 31(1), pp. 105-136.

[11] A. H. Crespo, I. R. del Bosque, and M. M. G. de los Salmones Sanchez, "The influence of perceived risk on 
Internet shopping behavior: a multidimensional perspective," Journal of Risk Research, 2009, 12(2), pp. 259-277.

[12] K. Z. K Zhang, S. J. Zhao, C.M.K. Cheung, and M. K. O. Lee, "Examining the influence of online reviews on consumers' decision-making: A heuristic-systematic model," Decision Support Systems, 2014, 67, pp. 78-89.

[13] B. Gu, J. Park, and P. Konana, "Research Note-The Impact of External Word-of-Mouth Sources on Retailer Sales of High-Involvement Products," Information Systems Research, 2011, (23), pp. 182-196.

[14] N. Hu, J. Zhang, and P. A. Pavlou, "Overcoming the Jshaped distribution of product reviews," Communications of the ACM, 2009, 52(10), pp. 144-147.

[15] F. Zhu, and X. Zhang, "Impact of online consumer reviews on sales: The moderating role of product and consumer characteristics," Journal of Marketing, 2010, 74(2), pp. 133-148.

[16] G. A. Akerlof, "The market for" lemons": Quality uncertainty and the market mechanism," The Quarterly Journal of Economics, 1970, 84(3), pp. 488-500.

[17] P. Nelson, "Advertising as information," The Journal of Political Economy, 1974, 82(4), pp. 729-754.

[18] W. Boulding, and A. Kirmani, "A consumer-side experimental examination of signaling theory: do consumers perceive warranties as signals of quality?," Journal of Consumer Research, 1993, 20(1), pp. 111-123.

[19] P. Milgrom, and J. Roberts, "Price and advertising signals of product quality," The Journal of Political Economy, 1986, 94, pp. 796-821.

[20] T. Erdem, and J. Swait, "Brand equity as a signaling phenomenon," Journal of Consumer Psychology, 1998, 7(2), pp. 131-157.

[21] J. D. Wells, J. S. Valacich and T. J. Hess, "What signal are you sending? how website quality influences perceptions of product quality and purchase intentions," MIS Quarterly, 2011, 35(2), pp. 373-396.

[22] X. Hu, G. Wu, Y. Wu, and H. Zhang, "The effects of Web assurance seals on consumers' initial trust in an online vendor: A functional perspective," Decision Support Systems, 48(2), pp. 407-418.

[23] R. Martin, and M. Hewstone, "Social influence processes of control and change: Conformity, obedience to authority, and innovation," in: Sage handbook of social psychology, London: Sage, 2003, pp. 347-366.

[24] S. Moscovici, "Toward a theory of conversion behavior," in: Advances in experimental social psychology, New York: Academic Press., 1980, pp. 209-239.
[25] S. Chaiken, "The heuristic model of persuasion," in: Social influence: The Ontario symposium, J.M.O. M. P. Zanna, \& C. P. Herman (ed.), Hillsdale, NJ: Lawrence Erlbaum Associates, Hillsdale, NJ: Erlbaum., 1987, pp. 3-39. [26] W. Wood, S. Lundgren, J. A. Ouellette, S. Busceme, and T. Blackstone, "Minority influence: a meta-analytic review of social influence processes," Psychological Bulletin, 1994, $115(3)$, pp. 323-345.

[27] R. K. Teas, and S. Agarwal, "The effects of extrinsic product cues on consumers: perceptions of quality, sacrifice, and value," Journal of the Academy of Marketing Science, 2000, 28(2), pp. 278-290.

[28] C. Aqueveque, "Extrinsic cues and perceived risk: the influence of consumption situation," Journal of Consumer Marketing, 2006, 23(5), pp. 237-247.

[29] N. Lim, "Consumers' perceived risk: sources versus consequences," Electronic Commerce Research and Applications, 2003. 2(3), pp. 216-228.

[30] D. M. Mackie, "Systematic and nonsystematic processing of majority and minority persuasive communications," Journal of Personality and Social Psychology, 1987, 53(1), p 41-52.

[31] M., Deutsch, and H. B. Gerard, "A study of normative and informational social influences upon individual judgment," The Journal of Abnormal and Social Psychology, 1995, 51(3), pp. 629-636.

[32] W. B., Dodds, K. B., Monroe, and D. Grewal, "Effects of price, brand, and store information on buyers' product evaluations," Journal of Marketing Research, 1991, 28(3), pp. 307-319.

[33] P. A. Pavlou, "Consumer acceptance of electronic commerce: Integrating trust and risk with the technology acceptance model," International Journal of Electronic Commerce, 2003, 7(3), pp 101-134.

[34] S., Cai, and Y. Xu, "Designing Product Lists for ECommerce: The Effects of Sorting on Consumer Decision Making," International Journal of Human-Computer Interaction, 2008, 24(7), 2008, pp. 700-721.

[35] C.W. Chen, "Five-star or thumbs-up? The influence of rating system types on users' perceptions of information quality, cognitive effort, enjoyment and continuance intention" Internet Research, 2017, 27(3), pp. 478-494.

[36] C.W. Park, and B. J. Moon, "The Relationship between Product Involvement and Product Knowledge: Moderating Roles of Product Type and Product Knowledge Type," Psychology and Marketing, 2003, 20(11), pp. 977-997. 